\title{
La ciudad a través del algoritmo
}

\author{
Javier Mazza
}

Javier Mazza::

Departamento de

Comunicación y

Departamento de

Formación Humanistica,

Facultad de Ciencias

Humanas, Universidad

Católica del Uruguay,

Uruguay.

javier.mazza@ucu.edu.uy
RESUMEN

El artículo utiliza el caso de Waze (navegador GPS que incorpora la lógica de funcionamiento de una red social) como punto de partida para reflexionar sobre la manera en la que la interacción tecnológica modifica nuestra relación con el entorno que nos rodea.

Palabras clave: inteligencia artificial (IA), Waze, GPS, redes sociales, algoritmo, smartphone, tecnología, internauta, interactividad.

\section{Introducción}

Nací en Montevideo y he vivido aquí desde entonces. Incluso puedo decir que he vivido casi exclusivamente en el mismo barrio donde hoy además trabajo. Tengo treinta y cinco años y he transitado por las calles de mi barrio en incontables ocasiones. Esas calles fueron escenario de importantes acontecimientos de mi vida. Puedo decir, sin miedo a equivocarme, que las conozco bien.

Como conductor se puede decir que tengo un buen dominio de las calles de la ciudad. No solo en los trayectos más habituales, sino también para trasladarme a lugares más alejados de mi zona de confort. Vale aclarar en este punto que, en mi juventud, uno de mis primeros trabajos consistía en entregar paquetes en distintas zonas de la ciudad; para ello conducía una camioneta y debía orientarme y planificar las rutas.
ABSTRACT

Taking waze (GPS navigator for smartphones with social media add-ons) as a starting point, this piece reflects upon the way in which interaction with technological devices shapes our relationship with ourenvironment.

Keywords: artificial intelligence (Al), waze, GPS, social media, algorithm, smartphone, technology, internet user, interactivity.

Hace tres años que tengo un smartphone. Si bien técnicamente soy un inmigrante digital, me manejo bastante bien con la tecnología, mejor que muchos de mis congéneres, aunque quizás no tan bien como mis alumnos, nativos digitales en su amplia mayoría (Winocur, 2012). Cuando cambié mi viejo teléfono celular por mi actual smartphone, poco a poco empecé a familiarizarme con sus numerosas aplicaciones (apps). Uno de los primeros aspectos que me deslumbraron fue la posibilidad de manejar mi correo electrónico a través del teléfono, pero la mensajería online (WhatsApp, Viber y Facebook Messenger) no tardaría en llegar, así como otras muchas apps: la agenda online (Google Calendar), la lista de tareas (Any.D0), la lectura de las noticias (Feedly), los cuadernos de notas online (Evernote) y la música online (Spotify). Una de las últimas apps en incorporarse a mi smartphone fue Waze. 


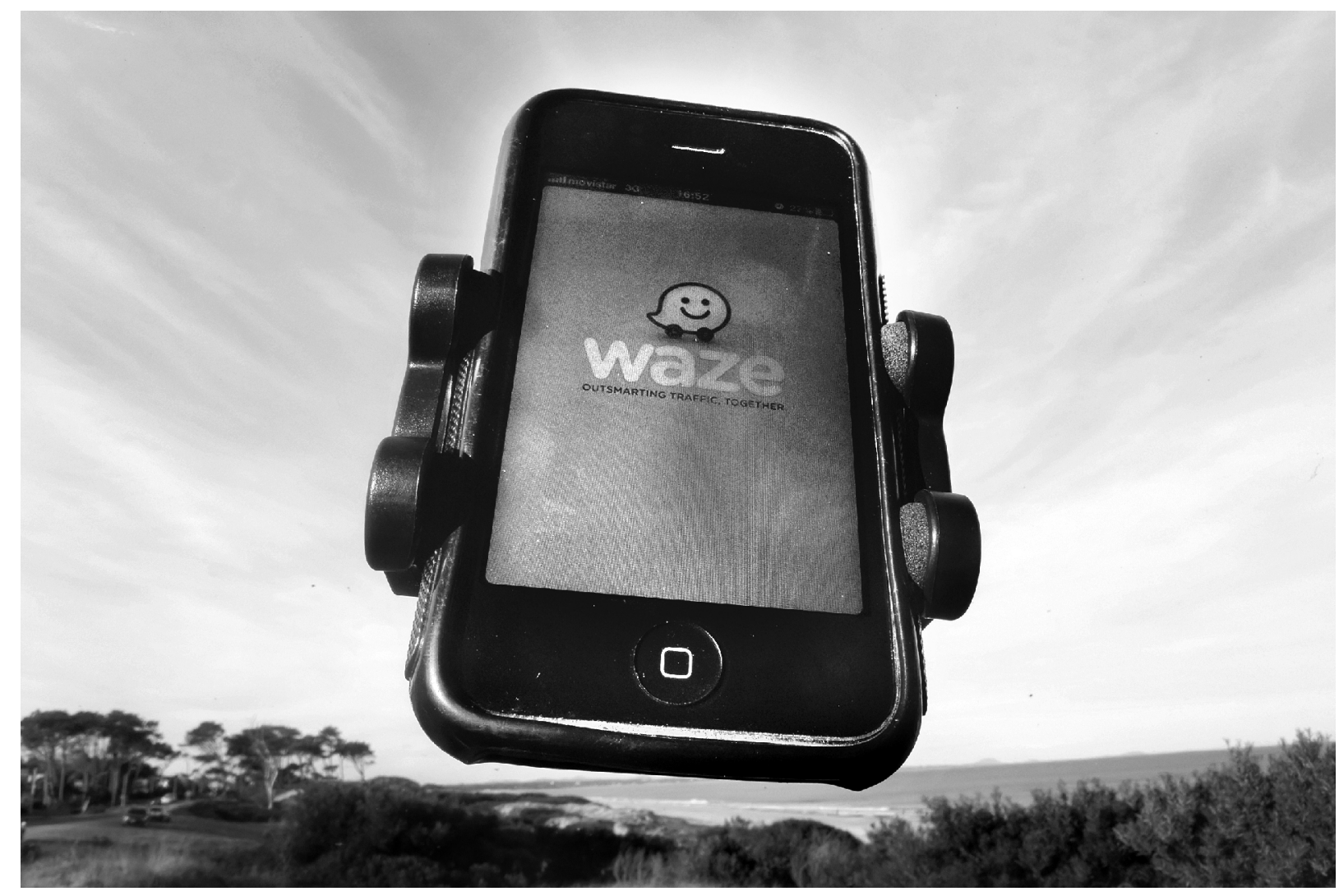

Waze es una aplicación que combina el rastreo satelital (GPS) con una plataforma similar a la de una red social. A través de una cuenta de usuario se puede ir compartiendo información sobre el estado del tráfico, accidentes, controles policiales, zonas propensas al siniestro del coche, cortes de ruta, calles en reparación y otras tantas posibilidades. Con toda esta información Waze genera un mapa interactivo (imagen 1) que todos los usuarios pueden ver a medida que se desplazan por la ciudad.

Sin embargo, como muestra la imagen 1, esto no es lo único que Waze puede hacer. Su función principal es operar como un navegador GPS. Le proporciono un punto de partida y un punto de llegada y Waze me sugiere una serie de rutas para trasladarme. El diferencial que Waze incorpora respecto al tradicional navegador GPS es su capacidad de procesar la información que obtiene de los usuarios y ofrecer como primera opción la que considera la "mejor ruta". De allí su eslogan: "Evitando el tráfico juntos" ("Outsmarting traffic together").

Mi primera experiencia con Waze fue por demás interesante. Instalé la aplicación por recomendación de un amigo, quien me dijo que era "muy útil". En un principio fui bastante escéptico: al fin y al cabo yo no necesitaba una app de GPS; sabía moverme más que bien en las calles de Montevideo. Sin embargo, terminé instalándola por curiosidad. La primera vez que la utilicé lo hice con la convicción de que iba a ganarle a Waze; por eso decidí probarla en mi traslado más habitual: desde mi casa hasta mi trabajo. Waze no podría generar una opción que superara mi ruta cotidiana. Además, conozco las alternativas con sus ventajas y desventajas, las he probado y evaluado y he llegado a la conclusión de que la ruta que escojo día tras día es sin duda la mejor. Me subí al coche, encendí la aplicación e ingresé los datos. A los pocos segundos confirmé mis sospechas: Waze se equivocaba. Entre las opciones que me ofrecía, mi ruta figuraba en quinto lugar, y no solo eso: la que ofrecía como mejor ruta yo sabía que era la peor. Me sonreí, apagué la aplicación y emprendí el camino por mi ruta cotidiana con la autosatisfacción de haber ganado una batalla más en la competencia con la tecnología.

Poco duró mi alegría. A mitad de camino, la calle por la que debía tomar, la que hacía que mi ruta fuese casi perfecta, estaba cortada por un accidente. No podía 


\section{Obtén la mejor ruta, todos los días, con la ayuda en tiempo real de otros conductores.}

\begin{abstract}
Waze es la aplicación de tráfico y navegación basada en la comunidad más grande del mundo. Únete a los conductores de tu área que comparten el tráfico e información de ruta en tiempo real ahorrando todos tiempo y dinero en sus desplazamientos diarios.
\end{abstract}

WAZE. EVITANDO EL TRÁFICO, JUNTOS

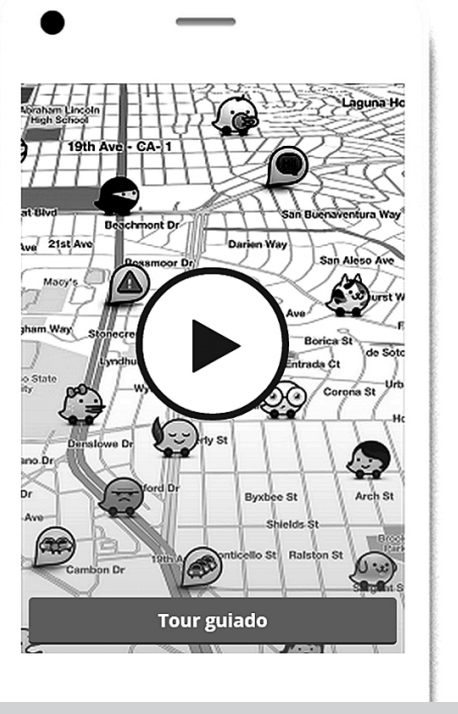

Imagen 1. Captura de www.Waze.com/es-419 el 28 de marzo de 2015 historia del Golem. Una buena recopilación se encuentra disponible en Schwartz (2004, pp. 279-283). Para una versión crítica de la historia y su significación se recomienda Idel (1990).

En la mitología grecorroman Prometeo es quien crea al hombre, moldeándolo del barro de la tierra. Luego, desafiando a Zeus, roba el fuego del monte Olimpo y se lo entrega a los hombres. A causa de ello sufre el castigo de permanecer eternamente encadenado a una roca en el Cáucaso, donde un ave lo tortura comiéndole el hígado dia tras día (Graves, 1955). Prometeo se convierte asi en un ejemplo de

lo que les sucede a quienes contravienen las leyes de los dioses. creerlo. Encendí Waze para ver si el accidente figuraba en el mapa interactivo y, efectivamente, allí estaba, marcado con una línea roja y un ícono de policía a su lado para avisar que también los agentes del orden habían acudido a la escena del siniestro (dato que yo ni siquiera podía corroborar desde donde estaba parado con el auto). Me maldije una y cien veces, a mí y a mi soberbia, y embargado de vergüenza introduje nuevamente los datos en Waze: dónde me encontraba y hacia dónde me dirigía. En lo que parecía una ironía del destino (porque, que yo sepa, la app no tiene un sentido de la ironía, al menos no por ahora), Waze me decía que la mejor ruta seguía siendo la que me había ofrecido en primer lugar, solo que para tomarla ahora tendría que hacer un desvío importante. Era lógico: al fin y al cabo, no le había hecho caso en un principio y tenía que pagar las consecuencias.

La ruta sugerida resultó bastante buena y, por más que llegué al trabajo algo tarde, no era tan tarde como si hubiese esperado a que el tráfico se descongestionara en mi ruta. Realmente Waze había cumplido su promesa: utilizando la información proporcionada por otros conductores me había ayudado a evitar el tráfico y me había proporcionado la mejor ruta. Pero lo que no pude quitarme de la cabeza esa mañana fue que Waze me había vencido, Waze era más inteligente que yo y lo era de una manera en la que yo jamás podría llegar a serlo.
La vida en función del algoritmo

La idea de la inteligencia artificial es una idea romántica. Surgió en el siglo XIX en Inglaterra, en pleno auge del conocimiento científico. Ada Lovelace, hija de Lord Byron, considerada la madre de la informática, ya formulaba la pregunta metafísica fundamental en torno al tema: ¿pueden pensar las máquinas? (Isaacson, 2014). La inquietud no era patrimonio de Ada. El siglo XIX ya había explorado el dilema que se vincula a la pregunta de si las creaciones humanas pueden equipararse al espíritu humano. Es el germen del Frankenstein de Mary Shelley (1818), que no es más que una revisita a la leyenda del Golem, ${ }^{1}$ con la diferencia de que en su versión romántica el "autómata" no se fabrica de materia inanimada sino de restos humanos. Considerando la manera en que los conocimientos en medicina eran valorados en la época -como lo muestra Holmes (2008)-, podemos comprender de dónde surge la preocupación de Shelley, quien subtituló su novela "el moderno Prometeo", dándonos una clara pista de hacia dónde habrían de ir las interpretaciones. ${ }^{2}$

El mundo romántico tenía frescas las advertencias sobre los efectos que conlleva "jugar a ser como dioses". El Golem judío se había vuelto en contra de sus creadores y el monstruo del Dr. Frankenstein termina, tras provocarle la ruina, acabando con la vida de ambos. Cuando Ada Lovelace proyectaba los alcances 


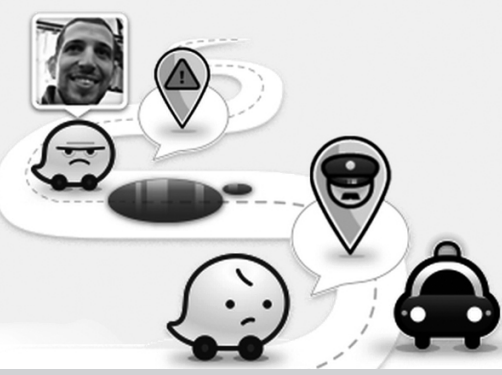

Imagen 2. Captura de https://www.Waze .com/es-419 el 28 de marzo de 2015
Nada puede vencer a personas reales trabajando juntas

Imagina millones de conductores en la calle, trabajando juntos hacia un objetivo común: ganarle al tráfico y tener la mejor ruta hacia el trabajo y de regreso, todos los días. de su "máquina analítica", ${ }^{3}$ se hacía eco de estas preocupaciones:

La máquina analítica no tiene en absoluto pretensión alguna de originar nada [...] Puede hacer cualquier cosa que sepamos cómo ordenarle que realice. Puede desarrollar análisis, pero no tiene capacidad alguna de anticipar cualesquiera relaciones o verdades analíticas (Lovelace, citada en Isaacson, 2014, p. 44).

$\mathrm{Al}$ decir que "La máquina analítica no tiene en absoluto pretensión alguna de originar nada”, Ada se previene: aclara que su invención no contraviene el sacro principio de "dar vida", función reservada a los dioses y que en manos de los hombres solo puede traer perjuicios, como bien mostraban los mitos (Prometeo y el Golem) y sus revisitas (Frankenstein). Hoy, casi doscientos años después, las preguntas de Ada, las preocupaciones de los románticos y las advertencias de los mitos vuelven a cobrar relevancia.

El argumento es bastante sencillo. En este momento tenemos a nuestra disposición mucha más información de la que podríamos llegar a procesar a lo largo de toda nuestra vida. Ningún cerebro humano es capaz de procesar toda la información que está en este momento almacenada en la web y esa cantidad crece exponencialmente segundo a segundo. Si bien es cierto que el mismo diagnóstico se podría haber hecho en el siglo $\mathrm{XV}$ contando todos los volúmenes escritos y almacenados en una biblioteca cualquiera, la situación de hoy en día presenta algunas diferencias sustanciales. La información en la biblioteca ya se encontraba (de alguna manera) procesada por otro ser humano, mientras que un gran porcentaje de la información que se encuentra en la web es generada automáticamente por otras máquinas. El problema se torna más complejo si consideramos que, mientras los seres humanos no tenemos la capacidad de procesar toda esta información, las computadoras sí la tienen. Son, como dice Eric Sadin, una "potencia cognitiva superior".

Nuestro tiempo instaura una relación con la técnica que ya no está prioritariamente fundada sobre un orden protético, o sea, como una potencia mecánica superior y más resistente que la de nuestro cuerpo, sino como una potencia cognitiva en parte superior a la nuestra. Hay robots inmateriales "inteligentes" que colectan masas abismales de datos, las interpretan a la velocidad de la luz al tiempo que son capaces de sugerir soluciones supuestamente más pertinentes, e incluso de actuar en lugar nuestro, como ocurre con el trading algorítmico, por ejemplo (Sadin, 2013).

Sadin introduce aquí un elemento clave: no solo las computadoras pueden interpretar toda la información disponible como jamás podríamos hacerlo, sino que además tomamos decisiones basadas en dicho procesamiento, cuando no automatizamos las decisiones y les permitimos a las computadoras tomarlas por sí mismas. ${ }^{4}$ Es que cuando optamos por las sugerencias de la computadora habitualmente salimos beneficiados; los beneficios que obtenemos son mayores porque cuentan con el soporte del procesamiento de datos del algoritmo. Según dice Waze, es el conjunto de los usuarios el que arriba a la decisión de la mejor ruta posible (imagen 2), pero ¿estamos pensando en conjunto o es el algoritmo el que piensa por nosotros?

La respuesta a la pregunta anterior resulta bastante obvia en virtud de lo expuesto hasta este punto: el
Máquina analítica fue el nombre que Ada Lovelace y Charles Babbage habian acuñado para denominar la que sería considerada como uno de los primeros prototipos de máquina computadora de la historia.

Sadin menciona el trading algoritmico, una de las causas principales de la última crisis económica norteamericana. Pero un caso más accesible que ilustra esta situación es la aplicación IFTII (If This Then That), que automatiza una serie de decisiones basándose en acciones determinadas que realizamos con otras aplicaciones del teléfono móvil. Podemos automatizar que cada vez que tomamos una foto la app se encargue de publicarla en Facebook y luego almacenarla en nuestra carpeta de Dropbox. Para más datos véase su sitio web, https://ifttt.com/ 
algoritmo piensa por nosotros y nosotros aceptamos sus sugerencias, y lo hacemos porque sabemos que sus conclusiones son mejores que las nuestras ya que tiene mayores fundamentos para decir lo que dice. De alguna manera esto implica delegar nuestra voluntad en las máquinas. En palabras de Sadin:

La asistencia de las existencias por sistemas “inteligentes”, además de que representa una evolución cognitiva, redefine de facto la figura de lo humano como amo de su destino en beneficio de una delegación progresiva de nuestros actos concedida a los sistemas. Una creación humana, las tecnologías digitales, contribuyen paradójicamente a debilitar lo que es propio al ser humano, o sea, la capacidad de decidir conscientemente sobre todas las cosas (Sadin, 2013).

Parecería que la prevención de Ada ha sido hace tiempo transgredida. Nuestras máquinas analiticas hace tiempo que generan cosas por sí solas. No lo he hecho aún, pero puedo mantener Waze encendido mientras manejo. El GPS le proporciona automáticamente la información que necesita y la aplicación me provee de sugerencias a medida que me muevo por las calles de la ciudad, por más que no haya ingresado una ruta de antemano. ¿Debemos temer que se avecine el momento de la singularidad albergando miedos cuasiapocalípticos? Me parece un poco exagerado. Sin embargo, creo que la pregunta que cabe formularse es: ¿cuáles son las consecuencias de toda esta situación en nuestra vida cotidiana?

Sherry Turkle trabaja como antropóloga y psicóloga en el MIT desde fines de la década de los ochenta. Su primera obra sobre las relaciones entre los seres humanos y la tecnología se tituló The Second Self. Computers and the Human Spirit (Turkle, 1984). Aquí expone su tesis de la computadora como un objeto evocativo, un medio que habilita al espíritu humano a proyectarse, que "crea las condiciones para que sucedan otras cosas” (Turkle, 1984, p. 20). Es una visión optimista que augura un futuro prometedor para la relación con la tecnología. Once años más tarde publicó Life on Screen. Identity in the age of the internet (Turkle, 1995). En esta segunda obra, algunas preocupaciones iniciales que ya albergaba en 1984 se vuelven más visibles. Sin embargo, en sus conclusiones termina diciendo:

La contienda final se refiere a la noción de lo real. [...] [E]n los ordenadores en red de nuestra vida cotidiana, la gente tiene convincentes interacciones que son completamente dependientes de las representaciones electrónicas de sí mismas. En el ciberespacio, cientos de miles, quizás millones de usuarios crean personajes electrónicos que viven en un grupo diverso de comunidades virtuales en las que la rutina de la formación de múltiples identidades mina cualquier noción de un yo real y unitario. Sin embargo, la noción de lo real contraataca; las personas que viven vidas paralelas en la pantalla están, por otra parte, atadas por los deseos, el dolor y la mortalidad de sus yos físicos. Las comunidades virtuales ofrecen un contexto totalmente nuevo en el que pensar sobre la identidad humana en la era de Internet. Son espacios de aprendizaje sobre el significado vivido de una cultura de la simulación. ¿Será un mundo separado en el que las personas se pierdan en superficies o aprenderemos las formas en que lo real y lo virtual se pueden hacer permeables, cada uno teniendo potencial para enriquecer y expandir al otro? (Turkle, 1995, pp. 336-337). 
En el 95 Turkle se inclinaba por la segunda opción. Si bien el panorama era distinto al del 84, aún albergaba esperanzas para el desarrollo de las relaciones entre el mundo offline y el mundo online que había expandido las relaciones entre el selfy la computadora como second self. En 2011 Sherry Turkle publica Alone Together. Why do we expect more from technology and less from each other (Turkle, 2011): el entusiasmo en torno a las relaciones entre seres humanos y tecnología se ha transformado en decepción. "Aparentemente estamos determinados a otorgarles cualidades humanas a los objetos mientras nos contentamos con tratarnos como cosas los unos a los otros" (Turkle, 2011, p. xiv, traducción propia). Parece obvio que, para Turkle, el potencial enriquecimiento del mundo virtual al mundo real devino en un empobrecimiento de las relaciones humanas. En sus propios términos, otorgamos cualidades humanas a los objetos tecnológicos porque cada vez esperamos más de ellos y menos de nosotros mismos o de los demás. La pregunta que cabe formularse entonces es: ¿por qué esperamos más de la tecnología? Desde el punto de vista que hemos desarrollado podríamos decir que es porque, en este estadio de su desarrollo, la tecnología es capaz de pensar de una manera en la que nosotros no podemos hacerlo y sus conclusiones superan las nuestras. Podríamos decir entonces que Waze tiene, en lo que respecta a la evaluación del tráfico, un mejor "cerebro" que nosotros, proporcionado por el algoritmo con el que procesa la información, y tiene mayor "visión" que nosotros ya que puede integrar la información de todos los conductores en tiempo real.

Si trasladamos esto a los diferentes aspectos de nuestras vidas, no tardaremos mucho en darnos cuenta de cómo esta situación podría llevarnos a una importante pérdida de la autonomía (Turkle, 2014). Sin ir tan lejos, sí podemos decir que la relación con la tecnología introduce cambios significativos en la manera que tenemos de experimentar el mundo que nos rodea. Quisiera ilustrar este punto con otra reflexión sobre mi experiencia personal.

En el año 2000 visité la ciudad de Florencia. El objeto del viaje era simplemente hacer turismo, por lo que, una vez llegado al lugar, compré una guía para viajeros, una Eyewitness Guide -bastante visual, como lo indica el nombre-, que proponía recorridos a través de distintos sectores de la ciudad, me decía qué "había que ver” y cuánto tiempo y dinero invertiría en el recorrido.

En 2015 visité la ciudad de Nueva York. El objeto del viaje no era exclusivamente hacer turismo, pero reservé buena parte de mi tiempo para ello. La tecnología utilizada para recorrer la ciudad había cambiado significativamente en quince años. En lugar de la Eyewitness - que podría haber comprado ya que aún existen y se venden muy bien-, mi asistente para moverme por la ciudad fue Google Maps (no estaba manejando, por lo que no utilicé Waze), el que me decía qué camino recorrer, en qué medio de transporte y cuánto tiempo tardaría en llegar a mi destino.

Mis dos experiencias de viaje fueron significativamente diferentes y mi visión de estas dos ciudades permanecerá permeada por ellas. En la visita a Florencia, asistida por la tecnología del libro, puedo decir que me sentía como un lector. Allí me encontraba, interpretando la ciudad que se desplegaba ante mis ojos asistido por las sugerencias de la guía, pero librado a mi lectura de lo que veía. A lo sumo podría decir que funcionaba como espectador, la ciudad como texto, como imágenes que "van existiendo a medida que el lector o el espectador los usa o los reinterpreta" (García Canclini, 2007, p. 73). En la visita a Nueva York, de la 


\section{Vuelven las sorpresas viales de Pascuas}

Published 2/26/2015

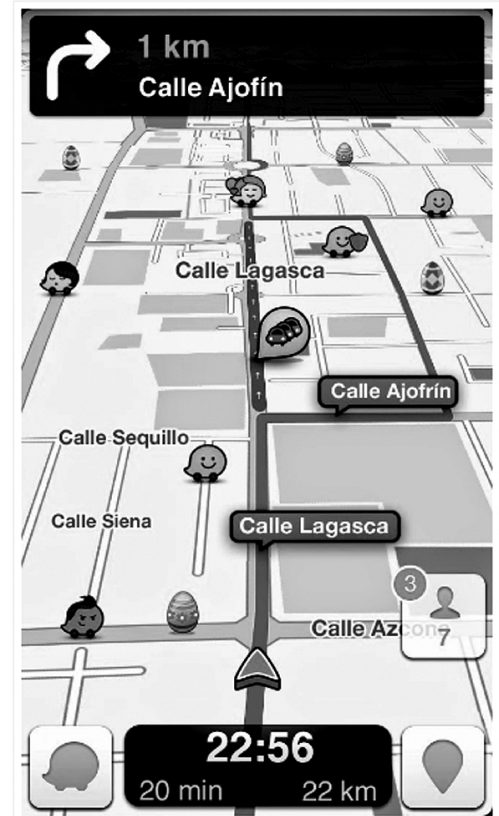

La celebración de Pascuas está a la vuelta de la esquina y no se nos ocurrió una mejor forma de hacerlo que con una buena Caza de Huevos de Pascuas al viejo estilo. Es por esto que del 26 de marzo al 5 de abril, verán huevitos de Pascuas en los mapas de Waze. ¡Cada huevito vale 3 puntos!

Para 'comer' el huevo sólo tienes que conducir sobre el ícono mientras usas Waze.

Puedes ver cuántos puntos has acumulado presionando Menú - Mi Waze - Tabla de posiciones.

Por supuesto si prefieres no ver estos huevitos sobre el mapa, siempre puedes desactivarlos yendo a Ajustes - visualización Mostrar en Mapa - Sorpresas viales off.

Esperamos que estos agregados al estilo Waze ayuden a entrar en el ambiente festivo mientras están en su ruta.

¡Felicidades Wazers!

Imagen 3. Captura de blog-es.waze.com el 28 de marzo de 2015

mano de Google Maps, iba de un lugar a otro, pensando sobre todo en el destino, despreocupado o prestando poca atención al camino como experiencia y preocupado por seguir adecuadamente las indicaciones de la aplicación. De alguna manera me encontraba en el modelo del consumidor, interactuando con la ciudad pero para absorberla, demandándole que me diera objetos de consumo a medida que la recorría.

Reflexionando sobre estas experiencias puedo decir que el cambio de una a la otra es el pasaje del modelo del lector al modelo del internauta. Creo que es impropio en este punto caer en la dicotomía de emitir juicios de valor sobre uno y otro modelo. Estoy convencido de que uno de los problemas más importantes que tiene la crítica cultural contemporánea es la polarización constante que hace del mundo de la tecnología: o la panacea de la libertad o el infierno de la esclavitud. Estas polarizaciones nos nublan la vista y ponen el juicio de valor por delante de la apreciación de la diferencia efectiva que existe entre las cosas. De lo que debemos ser conscientes es de que el modelo cambia. En el modelo del internauta se "proporciona simultáneamente interactividad interna y deslocalización, conocimientos y nuevas dudas. El carácter multimodal de la comunicación inalámbrica modifica las formas antes separadas de consumo e interactividad al combinarlas en un mismo aparato" (García Canclini, 2007, p. 75). En cam- 
bio, el modelo del lector supone otros códigos, otras maneras de relacionarse con el objeto leído. Se abre la puerta a la interpretación, pero este mecanismo no nos proporciona el mismo tipo de interactividad que tendríamos como internautas y también nos inhibe (aunque no completamente) la capacidad de consumo.

Para culminar quiero volver a Waze para mostrar cómo la aplicación se presenta ante nosotros dentro del modelo del internauta, tal como lo describe García Canclini.

La imagen 3 no es una captura de una pantalla de videojuego, por mucho que pueda parecerlo. Muestra el desafío de Pascua que Waze propone a sus usuarios: cazar huevos de Pascua virtuales a medida que transitamos por las calles reales de nuestra ciudad. Interactividad interna al evaluar y reformular nuestra ruta para cazar los huevos; deslocalización para desplazarnos en esa hibridación del mundo real con el mundo virtual que nos propone la aplicación; conocimiento e incertidumbre, saber y no saber dónde encontraremos el próximo huevo de Pascua virtual. Y, por último, la que quizás sea la característica más relevante de este modelo: el consumo interactivo, consumir huevos de Pascua virtuales (recordemos que " $\mathrm{iCada}$ huevito vale 3 puntos!") a medida que interactuamos con el mapa virtual y las calles reales de la ciudad.

No podemos decir que el modelo del lector ha de ser preferido por encima del modelo del internauta. Lo cierto es que ambos modelos plantean relaciones distintas con el mundo a través de distintas mediaciones tecnológicas. Podemos saber de qué se trata cada uno de ellos y optar (en la medida de lo posible) por vivir de acuerdo a los códigos de uno o del otro. Creo que los peligros que temen los apocalípticos de la tecnología proceden más de la carencia de conciencia de a qué códigos nos sometemos con cada modelo que de las consecuencias reales de su uso.

Mientras tanto, he dejado de usar Waze para ir a trabajar, pero no he dejado de usar Waze.:-

\section{Bibliografía}

García Canclini, N. (2007). Lectores, espectadores e internautas. Barcelona: Gedisa.

Graves, R. (1955). The Greek Myths (vol. 1). Londres: Penguin.

Holmes, R. (2008). La edad de los prodigios. Terrory belleza en la ciencia del Romanticismo. Madrid:Turner Noema.

Idel, M. (1990). Golem. Jewish Magical and Mystical Traditions on the Artificial Anthropoid. Nueva York: State University of New York Press.

Isaacson, W. (2014). Los innovadores. Los genios que inventaron el futuro. Buenos Aires: Debate.

Sadin, E. (2013). Las tecnologías digitales debilitan la capacidad de decidir. Página 12. Recuperado de http://www.pagina12. com.ar/diario/sociedad/3-233880-2013-11-19.html

Schwartz, H. (2004). Tree of Souls. The Mythology of Judaism. Nueva York: Oxford University Press.

Sheeley, M. (1818). Frankenstein. Or the Modern Prometheus. Londres: Penguin.

Turkle, S. (1984). The Second Self. Computers and the Human Spirit. Cambridge: The MIT Press.

Turkle, S. (1995). La vida en la pantalla. La construcción de la identidad en la era de internet. Barcelona: Paidós.

Turkle, S. (2011). Alone Toghether. Why do We Expect More From Technology And Less From Each Other. Nueva York: Basic Books.

Turkle, S., y Fischetti, M. (2014). The Networked Primate. Scientific American, 311(3): 82-85.

Winocur, R. (2012). Inmigrantes y nativos digitales: una alteridad sin interlocutor. México: MUAC. 